\title{
LOS SILENCIOS EN LA MEMORIA. NARRATIVA DE LA VIOLENCIA SEXUAL EN LA COMISIÓN DE LA Verdad y ReCONCILIACIÓn de PERÚ
}

\section{Silences in Memory. Narrative of Sexual Violence in The Truth AND ReCONCILIATION Commission of Peru}

\section{Sandra Marcela Arvesú Juárez ${ }^{1}$}

Resumen: El conflicto armado interno que asoló Perú durante las décadas de 1980 y 1990 tuvo diversas y devastadoras consecuencias para mucha de la población civil y de manera particular para las mujeres. De acuerdo con el Informe Final de la Comisión de la Verdad y Reconciliación de Perú - CVR-, la violencia sexual fue el principal crimen cometido en contra de ellas, considerado por primera vez en un país latinoamericano como una violación a los derechos humanos y, dado su carácter generalizado, un crimen de lesa humanidad. De ahí el interés de reflexionar en este artículo sobre el tema de la violencia sexual durante el conflicto armado interno en Perú desde la perspectiva de los estudios de la memoria, con el objetivo de analizar la narrativa construida por la Comisión sobre la violencia sexual y al mismo tiempo problematizar cómo se recuerda, quiénes recuerdan, y qué alcance ha tenido su reconocimiento como parte de la memoria histórica del conflicto.

Palabras clave: conflicto armado, violencia sexual, mujeres, memoria, testimonio, Perú.

\footnotetext{
${ }^{1}$ Licenciada en estudios latinoamericanos por la UNAM, maestrante en estudios latinoamericanos, UNAM. Líneas de investigación: violencia de género, Perú, Comisión de la verdad, estudios de la memoria. Correo electrónico: arvesu3@hotmail.com Fecha de recepción: 0511 15; Fecha de aceptación: 230316.
}

(cc) EY-NC-ND Páginas 49-78. 
Abstract: The internal armed conflict that affected Peru during the 1980s and 1990s had diverse and devastating consequences for civilian population and in particular for women. According to the Final Report of the Truth and Reconciliation Commission of Peru - TRC - , sexual violence was the main crime committed against women, and it was considered for the first time in a Latin American country as a human rights violation and, given its widespread nature, a crime against humanity. Hence, the interest of reflecting on this article about the topic of sexual violence during the internal armed conflict in Peru from the perspective of the studies of memory, with the aim of analyzing the narrative constructed by the Truth and Reconciliation Commission - TRC - about sexual violence and at the same time, to discuss about how it is remembered, by whom and what scope its recognition has had as part of the historical memory of conflict.

Keywords: armed conflict, sexual violence, women, memory, testimony, Peru.

\section{Introducción}

Durante las últimas décadas del siglo XX, cuando dieron fin los gobiernos autoritarios y las dictaduras militares en América Latina, se desarrollaron interesantes procesos de transiciones a la democracia, los cuales fueron acompañados de ejercicios oficiales de investigación sobre el pasado reciente, conocidos de manera genérica como Comisiones de la verdad. Si bien estos trabajos poseen características particulares - en la integración de sus miembros, en la constitución del mandato, en sus metodologías, en la duración de la investigación y alcances, entre otras-, tuvieron como objetivo común esclarecer los hechos del pasado violento o la búsqueda de la "verdad" respecto a las violaciones a los derechos humanos ocurridas durante los regímenes autoritarios.

Una característica central y común de estos ejercicios fue la recopilación de testimonios para la reconstrucción de los hechos así como la recuperación de la memoria de las víctimas. Para que lo anterior fuera posible no bastó con la intención del trabajo oficial de estas Comisiones, 
pues en buena medida fueron las Organizaciones No Gubernamentales, que impulsaban la defensa de los derechos humanos, y sobre todo las organizaciones de los familiares de detenidos y desaparecidos, quienes defendieron con más encono el derecho a la memoria de las víctimas —Elizabeth Jelin les llama "gestores de memoria" - . Esto se enmarcó también en la pugna que surgió entre memorias hegemónicas versus memorias subalternas.

Los momentos de cambio de régimen político, los periodos de transición, crean un escenario de confrontación entre actores con experiencias y expectativas políticas diferentes, generalmente contrapuestas. Y cada una de esas posturas involucra una visión del pasado y un programa -implícito en muchos casos- de tratamiento de ese pasado en la nueva etapa que es definida como ruptura y cambio (Jelin, 2002: 45).

Sin duda, la postura más fuerte se estableció como un imperativo ético desde el surgimiento de la primera comisión en Argentina: "recordar para no repetir", o como se inscribió en el informe Nunca Más, "para 'no repetir', se debía mantener viva la memoria" (Jelin, 2003: 15). De ese modo, las Comisiones de la verdad se colocaron en el centro del debate reciente sobre la memoria en América Latina. Aunque existen diversas aproximaciones y un intenso debate — desde la historia, la psicología, la sociología, la antropología— ${ }^{2}$, para efectos del interés que aquí nos ocupa, nos limitaremos a señalar que: “... se entiende por memoria al proceso de dar sentido y significado a una experiencia ... a las formas de como la gente recuerda el pasado desde el presente ... memoria es entendida en este caso como un proceso intersubjetivo y dialógico entre individuos y sociedad, dentro de sistemas de valores y creencias, y anclado en experiencias y formas de representación” (Del Pino, 2004: 12).

2 Interesantes trabajos que constituyen pilares sobre el tema son el de Maurice Halbwachs (2004), Los marcos sociales de la memoria; de Paul Ricoeur, La memoria, la historia y el olvido (2010) y La lectura del tiempo pasado: memoria y olvido (1999); de Jacques Le Goff (1991), El orden de la memoria: el tiempo como imaginario; de Tzvetan Todorov (2000), Los abusos de la memoria; y de Elizabeth Jelin (2002), Los trabajos de la memoria. 
Entendida así, la memoria es un proceso situado en una relación temporal entre pasado, presente y futuro, en el que se rememora un suceso al que se le confiere un sentido desde el aquí y el ahora, y a partir del cual se proyecta una intención. A menudo ese futuro tiene que ver con el acceso a la justicia y la vindicación de ciertos derechos. Además, "el acontecimiento rememorado o 'memorable' será expresado en una forma narrativa, convirtiéndose en la manera en que el sujeto construye un sentido del pasado, una memoria que se expresa en un relato comunicable, con un mínimo de coherencia" (Jelin, 2002: 27). Es importante advertir que ese proceso de dar sentido al pasado también es un ejercicio selectivo en el que recuerdo y olvido forman parte de una interacción dialógica, como lo señala Jelin:

... el olvido y el silencio ocupan un lugar central. Toda narrativa del pasado implica una selección. La memoria es selectiva ... Esto implica un primer tipo de olvido "necesario" para la sobrevivencia $\mathrm{y}$ el funcionamiento del sujeto individual y de los grupos y comunidades. Pero no hay un único tipo de olvido, sino una multiplicidad de situaciones en las cuales se manifiestan olvidos y silencios, con diversos "usos" y sentidos (ídem: 29).

Parte de la multiplicidad de situaciones a que se refiere incluye los posibles olvidos intencionales de la historia, y subraya que en el plano de las memorias individuales "el temor a ser incomprendido también lleva a silencios". Así, el silencio y el olvido se convierten en otra arista de la memoria, sin dejar de ser parte de ella.

Ponciano del Pino (2004) sugiere que también existen "experiencias que no se eslabonan en las narrativas que quedan olvidadas como experiencia", refiriéndose a aquellas que no logran articularse en las representaciones políticas o colectivas, permaneciendo como memorias sueltas. Por alguna razón esas memorias no pueden ser significadas. En términos de Jelin, cuando a las vivencias no se les puede dar sentido lo que persiste es el trauma: "Los acontecimientos traumáticos conllevan grietas en la capacidad narrativa, huecos en la memoria ... es la incapacidad de dar sentido al acontecimiento pasado, la imposibilidad de 
incorporarlo narrativamente, coexistiendo con su presencia persistente y su manifestación en síntomas, lo que indica la presencia de lo traumático" (2002: 28). El problema con el trauma es que éste diluye los contornos del ser social (Braunstein, 2012), y por ende su capacidad para narrarse a sí mismo.

La narración adquiere un papel central en la recuperación de la memoria, y a menudo se presenta en forma de testimonio. Por ello, es necesario aquí mencionar que los estudios sobre la memoria "ponen de relieve lo subjetivo y dan importancia al discurso", mostrando rechazo a las grandes narrativas históricas y priorizando los discursos alternativos (Maceira y Rayas, 2011).

De ahí la importancia que en las últimas décadas ha cobrado el testimonio como "novedosa fuente de información" que nos permite "escuchar la voz" de una multiplicidad de sujetos a menudo excluidos de los relatos históricos. Siguiendo a Beatriz Sarlo, “... el testimonio ha devuelto la confianza a esa primera persona que narra su vida - privada, pública, afectiva, política-, para conservar el recuerdo o para reparar una identidad lastimada" (2005: 22). El testimonio se presenta así como fragmentos de historias de vida, recoge la experiencia vivida de las personas e introduce las subjetividades en los registros históricos.

En suma, la memoria involucra recuerdos y olvidos, narrativas y actos, silencios y gestos. Hay en juego saberes y también hay emociones. De igual manera, huecos y fracturas (Jelin, 2002). Una última acotación necesaria es precisar porqué hablaremos de memoria histórica cuando los debates en torno a estos temas enfatizan la separación entre historia y memoria. Vale la pena subrayar que no son lo mismo, por ende, no se las debe confundir. La primera es una disciplina, la otra un proceso; la historia se inscribe en el terreno de la objetividad, mientras que la memoria lo hace en el de la subjetividad, no obstante ambas comparten la preocupación por la elaboración del pasado y producen narrativas. Aunque sus aproximaciones son muy distintas, compartimos la opinión de Paul Ricoeur (2010) y Enzo Traverso (2007) en el sentido de que la memoria ha acompañado el desarrollo de la historia o ha sido su motor. Entonces, se puede historiar y trabajar con fuentes orales, reconociendo las singularidades de cada una. 
La Comisión de la Verdad y Reconciliación de Perú —CVR, en adelante- construyó una narrativa que apeló a la creación de una conciencia histórica, combinando la investigación objetiva y cuantitativa con el análisis cualitativo de los testimonios, mismos que formaron parte medular de su trabajo. Al haber utilizado la fuente oral integró diversas memorias sobre el conflicto, al mismo tiempo que se potenció la elaboración de otras a partir de esa narrativa nacional, instituida como oficial. De ahí que haya sido importante retomar las nociones de memoria y testimonio, debido a que abordaremos la construcción de la memoria histórica relacionada con la violencia sexual contra las mujeres - de manera particular, con la violación — durante el conflicto armado interno en Perú.

Se parte de la premisa de Kimberly Theidon (2006) de que si existe un tema capaz de imponer silencio, es claramente el de la violación; experiencia difícil de enunciar por muchas razones, en ocasiones se presiona para que no se hable ni denuncie una violación, pero también persiste la autocensura por miedo, vergüenza, estigma y falta de canales de atención. ${ }^{3}$ Igualmente resulta necesario revisar la manera en que este tema y el testimonio de las víctimas fueron integrados en la narrativa construida por la Comisión de la Verdad y Reconciliación de Perú.

\section{El contexto}

En 1980 ocurrieron dos hechos significativos en la historia de Perú. El primero fue que tras doce años de gobiernos militares (1968-1980), Perú retornaba a un gobierno civil. El segundo, aunque paradójico en el nuevo contexto de retorno a la democracia, fue el inicio de un cruento conflicto armado interno que a lo largo de dos décadas cobró un saldo aproximado de 69,280 víctimas (CVR, 2003), un elevado porcentaje correspondió a población civil, mayoritariamente indígena y campesina, la cual quedó atrapada en el "fuego cruzado" entre las Fuerzas Armadas y los grupos subversivos - Partido Comunista de Perú-Sendero Luminoso (PCP-SL) y Movimiento Revolucionario Túpac Amaru (MRTA).

\footnotetext{
${ }^{3}$ Dadas las implicaciones que el silencio puede tener en acontecimientos de esta índole, se ahondará en ello más adelante.
} 
El conflicto comenzó con acciones armadas por parte de PCP-SL y tuvo como escenario principal la zona centro-sur de la sierra peruana, en donde se ubican lugares con altos índices de marginación; poco tiempo después, con el ingreso de las Fuerzas Armadas, la declaración de zonas de emergencia y la aparición de MRTA, el conflicto se extendió por casi todo el territorio peruano mediante una dinámica voraz, caracterizada entre otras cosas por el grado de violencia en el accionar de PCP-SL, que incluía ataques contra personal de las fuerzas armadas y policiales, al mismo tiempo que perpetraba crímenes contra minorías étnicas, autoridades civiles, líderes populares y contra todo aquel que se opusiera a su proyecto, generando un vacío de poder e involucrando a la población bajo su control a una guerra directa contra el Estado. Dicho sea de paso, esta característica que rompe con procesos similares en otros países de América Latina, en donde la violencia ejercida por el Estado siempre superó por mucho la de los movimientos armados, también sirvió de pretexto para justificar las atrocidades cometidas por las Fuerzas Armadas en contra de la población civil, en aras de la lucha antisubversiva. En suma, se le considera como el conflicto armado de mayor duración y el más costoso del siglo XX en esta nación andina.

Desde luego, las consecuencias resultaron devastadoras para el país, más aún, para la población indígena que habitaba principalmente en las zonas rurales de la sierra y la selva peruana. Miles fueron víctimas de innumerables crímenes y violaciones a los derechos humanos: asesinatos y masacres, desapariciones forzadas, ejecuciones arbitrarias, tortura y tratos crueles, violencia sexual contra las mujeres, violación del debido proceso, secuestro y toma de rehenes, violencia contra niños y niñas, y violación de los derechos colectivos, cometidos tanto por los grupos subversivos como por las fuerzas del Estado (CVR, 2003, Tomo VI). Es importante mencionar también que el conflicto armado aquejó gravemente a la población peruana en su conjunto, aunque se ha reconocido que afectó de manera diferenciada a mujeres y hombres.

De acuerdo con CVR, la violencia sexual resultó el principal crimen cometido en contra de ellas, y fue considerado por primera vez en un país latinoamericano como una violación a los derechos humanos; dado su carácter generalizado y sistemático se la determinó como un 
crimen de lesa humanidad. Lo anterior forma parte de las conclusiones presentadas en el Informe Final del trabajo realizado por CVR, a partir de las cuales se generó una narrativa nacional sobre la historia reciente de Perú que forma parte de la memoria histórica sobre el conflicto armado.

\section{Surgimiento de CVR y la Línea de género}

Después de dos décadas de un conflicto armado interno y de varios gobiernos corruptos e ineficientes, ${ }^{4}$ se formó en el año 2000 un gobierno transitorio a cargo de Valentín Paniagua, dándose inicio una nueva transición democrática en Perú. En 2001, durante dicho gobierno, se aprobó la creación de CVR para investigar lo ocurrido durante el conflicto armado. Si bien al crearse establecieron en su diseño y mandato los crímenes a investigar, no figuró en ellos la violencia sexual. No obstante que dicha práctica no haya sido expresamente mencionada se consideró bajo la forma de tortura y otras lesiones graves cuando los primeros avances de la investigación evidenciaron esta carencia. De tal modo que en los primeros meses del ańo 2002 los Comisionados acordaron incorporar la perspectiva de género como elemento importante en el trabajo de búsqueda de la verdad, al reconocer que el conflicto había impactado de manera diferenciada a hombres y mujeres. El documento signado señalaba:

... es fundamental reconocer los efectos que la violencia política tuvo en los hombres y las mujeres peruanas, entendiendo la manera diferenciada en que sus derechos humanos fueron afectados durante el período materia de nuestra investigación. Asimismo, debemos reconocer la existencia de la discriminación e invisibilidad de un

\footnotetext{
${ }^{4}$ El mismo año que estalló el conflicto ganó las elecciones Fernando Belaúnde Terry, quien a pesar de haber enviado a las Fuerzas Armadas a la sierra no logró frenarlo. En 1985 asumió la presidencia Alan García Pérez del Partido Aprista Peruano - APA—, quien además de haber priorizado la actuación militar en el desarrollo del conflicto, condujo al país a una crisis extrema; finalizó su mandato en medio de una hiperinflación de 7,200\%. En 1990 ganó la presidencia Alberto Fujimori, candidato independiente que enarboló un discurso de fuertes críticas a la clase política tradicional, pero que después de diez años de gobierno en el que dirigió un "auto golpe" de Estado, cobijó una gran red de corrupción que cada vez se hizo más evidente y que poco a poco fue restándole credibilidad ante la opinión pública. Abandonó el país en el año 2000.
} 
sector de la población —en este caso, de las mujeres- y a partir de esta situación diseñar las estrategias para incorporar de manera clara lo que les sucedió (CVR, 2002b).

A partir de ese momento surgió la línea de género como trabajo de la Comisión, cuyo propósito era dar cabida a la voz de las mujeres dentro de la memoria oficial sobre el conflicto armado, pues, como lo señalara Julissa Mantilla — coordinadora de la Línea de género y parte de la División legal de CVR - "debía reconocerse que las mujeres no habían tenido posibilidades de difundir sus historias y que su perspectiva de los hechos no sólo no se conocía sino que en muchas circunstancias había sido expresamente ignorada" (2006: 356), más aún cuando se trató de indígenas, monolingües, analfabetas y pobres.

En este sentido, es justo decir que CVR de Perú fue la primera en su tipo que incluyó la perspectiva de género para investigar los hechos ocurridos, determinar causas y efectos y, en consecuencia, establecer recomendaciones en materia de justicia y reparación. ${ }^{5}$ Esta consideración no es menor, si pensamos que las mujeres siempre han estado presentes en los conflictos armados - participando de muchas formas y sufriendo devastadoras consecuencias-, pese a ello han sido relegadas o excluidas de las grandes narrativas, de las decisiones, y de las negociaciones y acuerdos.

\section{Metodologías de trabajo}

Sin duda, algo que caracterizó a este trabajo fue el uso de testimonios como fuente primaria para la reconstrucción del pasado reciente. La misma Comisión afirmó en un balance realizado que: "El recojo de testimonios ha sido quizá la tarea más importante desarrollada por la comisión de la verdad, no sólo por el volumen de historias personales que hemos acopiado, sino también porque en esta actividad se expresa una opción deliberada de la comisión, que se desprende de la interpretación

\footnotetext{
${ }^{5}$ CVR de Perú tiene dos referentes importantes: la Comisión para el esclarecimiento histórico de Guatemala y la Comisión de la verdad y reconciliación de Sudáfrica, sólo que en éstas no se consideró la inclusión de la perspectiva de género como parte del mandato, aunque sí se incorporó un apartado sobre el tema en los informes finales.
} 
moral de nuestro mandato: recoger la voz de las víctimas en primer lugar" (CVR, s.f.).

Esto permitió la recuperación de diferentes memorias sobre el conflicto, en donde se incluyeron las voces más desdeñadas por la Historia oficial - por ejemplo, la de las mujeres y los indígenas, entre otras-. Para cumplir con el mandato de la Comisión, establecieron sedes regionales que trabajaron fundamentalmente con la recopilación de testimonios. Y aunque pudiéramos suponer que las personas atrapadas en una dinámica de violencia añoran ser escuchadas y que sus demandas sean atendidas, no siempre resulta fácil obtener los relatos, ya que brindar una entrevista o declarar en una audiencia pública implica sentirse observado, remover o traer de vuelta experiencias dolorosas, compartir o develar historias que se guardan en lo más íntimo, en suma, implica "exponerse" frente a otros. Por ello, el que se estableciera una línea de género tampoco garantizaba que de facto las mujeres acudirían a brindar sus testimonios o que accedieran a ser entrevistadas sin un mínimo de resistencia o recelo.

Para lograr su cometido, fue necesario estructurar una serie de acciones que permitieron al interior de la Comisión establecer una base sólida para el trabajo con las mujeres; por ejemplo, elaboraron guías para la toma de testimonios, realizaron talleres para capacitar y sensibilizar al personal que trabajó en cada sede y que realizó las entrevistas, luego efectuaron "talleres de género" con las afectadas, y entablaron relaciones con diversas organizaciones de mujeres que surgieron durante el conflicto y algunas ONG (Mantilla, 2006). Y como era ineludible para el éxito del trabajo de CVR que las mujeres aportaran sus testimonios, a la par de las medidas anteriores fue necesario realizar una amplia campaña:

La LDG [Línea de género] elaboró spots radiales, afiches y volantes informando sobre la necesidad de conocer las historias de las mujeres. Slogans del tipo "Mujer peruana, ven a dar tu testimonio", "Sin tu testimonio, la verdad no estará completa", "La verdad de las mujeres debe ser escuchada”, buscaban que las mujeres tomaran conciencia sobre la importancia de su rol en el proceso de recuperación de 
la verdad y la memoria. Adicionalmente, se prepararon textos, artículos y materiales informativos que se difundieron a nivel de los medios de comunicación nacionales ... se elaboró un folleto tipo cómic, destinado a difundir que la violencia sexual es una violación de derechos humanos ... La idea era presentar el tema de modo tal que las mujeres pasaran de ser víctimas a sobrevivientes, como un primer paso individual (ídem: 360).

Lo anterior explica hasta cierto punto el que en varios boletines y revistas abundaran las fotografías y los encabezados correspondientes a mujeres que perdieron a algún familiar, o que buscaban en alguna fosa, que portaban alguna fotografía o cartel sobre un desaparecido, etcétera, reforzando su imagen como "testigos".

De ese modo quedó establecido que el medio para recopilar los testimonios debía ser la entrevista y la realización de audiencias públicas. Las primeras tuvieron un carácter confidencial, mientras que las segundas consistieron en largas jornadas de trabajo dirigido por los comisionados, quienes — según la propia CVR - en una "sesión solemne" recibieron los testimonios. En las audiencias públicas no sólo estuvieron presentes las víctimas y los representantes de CVR, también contaron con la presencia de los medios de comunicación masiva que transmitieron en vivo cada una de las sesiones. A través de ese mecanismo, por primera vez las víctimas fueron vistas y escuchadas en todo el país. ${ }^{6}$ Posteriormente se hizo una ardua labor de divulgación de algunas de las actividades y sus resultados a través de entrevistas radiales. Sobre la importancia de los derechos de las mujeres, difundieron los videos de las audiencias públicas en las que ellas participaron y prepararon artículos sobre el tema en sus boletines locales (ídem). Todo ese trabajo dio como resultado que miles de peruanas acudieran

\footnotetext{
6 "Las Audiencias Públicas tienen como objetivos enriquecer la investigación, ampliar el espacio público y la agenda nacional, y crear oportunidades de sanación ... Las Audiencias Públicas fueron transmitidas en directo y a nivel nacional por Canal 7 de 12:00 a.m. a 1:00 p.m. Canal $\mathrm{N}$ emitió reportes continuos de cada una de las jornadas. El Perú fue testigo directo de una parte de nuestra historia que debemos reconstruir y no podemos olvidar" (CVR, 2002a: 3).
} 
a dar su testimonio ante CVR. De un total de 16,885 personas que lo brindaron, $54 \%$ fue del género femenino y $46 \%$, masculino. ${ }^{7}$

Sin duda, el establecer la línea de género, y la recepción tan amplia que se tuvo de testimonios de mujeres, permitió que se diera lo que Carlos Vargas (2011) denomina como "generización de la memoria"8 de CVR, así como de la memoria condensada en ella. Es decir, se logró una amplia participación de las mujeres en el ejercicio de la recuperación de la memoria.

\section{Apuntes de CVR sobre la violencia sexual durante el conflicto}

Una vez realizado el trabajo de campo, CVR debía integrar un informe final que presentara los resultados de la investigación y brindara algunas recomendaciones. En cuanto a los delitos de violencia sexual, particularmente en lo que se refiere a violaciones sexuales, debe subrayarse el esfuerzo que hizo CVR para integrarlos en su narrativa sobre el conflicto, toda vez que éstos habían sido ignorados hasta entonces. A ello se debe agregar que existen importantes subregistros, y señalar esto también fue importante: "la CVR considera que los delitos de violación sexual se encuentran subregistrados, por lo que las proporciones señaladas no representan, necesariamente, lo ocurrido en el universo de casos de violaciones de este tipo" (CVR, 2003, Tomo VIII: 67).

\footnotetext{
${ }^{7}$ De acuerdo con CVR, el porcentaje varía según el lugar donde se realizó la entrevista; el número de mujeres declarantes se incrementa en la zona del sur central y nororiental — 64\% en Ayacucho, 63\% en Huánuco y 61\% en Ucayali-, que forman parte de las zonas más afectadas por el conflicto y de las más pobres de país. También señala que una cuarta parte de las mujeres que dieron su testimonio - $24 \%$ - fue familiar directo de alguna víctima desaparecida, disminuyendo en el caso de los hombres - 12\%—; y subraya, además, que la diferencia de cifras no es casual y está relacionada con el hecho de que fueron las madres y hermanas de los desaparecidos - en su mayoría hombresquienes iniciaron los procesos de búsqueda y denuncia (CVR, 2003, Tomo VIII: 50).

${ }^{8}$ Carlos Vargas habla de "generización de la memoria" al considerar los aportes de las mujeres a la memoria colectiva/social. Refiriéndose a tres casos de Comisiones de la verdad — Guatemala, Sudáfrica y Perú - señala que éstas “fueron activas en los procesos de inclusión de las voces femeninas... reconociendo que la verdad, para que sea tal, debe ser una verdad generizada. La perspectiva de género buscada se reflejó en el número — mayoritario- de testimonios de mujeres" (Vargas, 2011).
} 
Es cierto que muchas mujeres brindaron su testimonio a CVR pero "pocas" denunciaron haber sido víctimas de violaciones sexuales. Consideremos que de casi 17,000 personas que testimoniaron, sólo 538 casos denunciaron violación sexual, de los cuales 527 corresponden a mujeres y 11 a hombres. ${ }^{9}$ Evidentemente esto representó un reto importante que fue sorteado gracias a un asiduo ejercicio de análisis e interpretación.

A pesar de que las cifras recogidas no muestran la magnitud del problema, los relatos, permiten inferir que las violaciones fueron una práctica común y bastante utilizada durante el conflicto. En innumerables relatos, luego de narrar los horrores de los arrasamientos y ejecuciones extrajudiciales y torturas, se señalan, al pasar, las violaciones a mujeres. En la medida que los testimoniantes no pueden dar los nombres de las mujeres afectadas, ellas no son "contabilizadas", a pesar de que se cuenta con el conocimiento de los hechos. Por lo dicho, la CVR destaca en este caso específico de violación sexual que, si bien numéricamente no puede demostrarse la amplitud de estos hechos, la información cualitativa y tangencial permitiría afirmar que la violación sexual de mujeres fue una práctica generalizada durante el conflicto armado interno ... Analizando los datos obtenidos a través de los declarantes, la CVR concluye que la violación sexual de mujeres se producía asociada a otras violaciones de derechos humanos como las detenciones, las desapariciones forzadas, las torturas y las ejecuciones extrajudiciales (ídem: 68).

Obviamente era complicado tener un registro certero si contemplamos tanto los impedimentos técnico-metodológicos — por ejemplo, sería

\footnotetext{
${ }^{9}$ Si para las mujeres es difícil hablar de una violación sexual es probable que lo sea más para los hombres; el estigma en unos y otros es distinto. Además no podemos perder de vista que en los imaginarios sobre la guerra generalmente se piensa que las mujeres son víctimas de este crimen y los hombres son los combatientes, por ello no es raro que esa realidad se invisibilice tanto en testimonios como en discursos. De ahí que nos parezca importante destacar que CVR incluyera este dato, pues la cifra en sí refleja la complejidad del tema. Sin duda éste es uno de los aspectos más incómodos y menos tratados cuando se reflexiona sobre los conflictos armados.
} 
difícil tener esa información basándose en las osamentas de mujeres asesinadas durante las masacres-, como los culturales - no reconocer que la violación sexual es un delito, o el miedo y la reticencia a denunciarlo, o no hablar siquiera de ello por el estigma generadoNo obstante, en el relato en que se incluyó y trabajó teniendo en cuenta la perspectiva de género, se infirió a partir de los testimonios - pese a todos sus problemas y subregistros- que las mujeres no sólo fueron víctimas de asesinatos y ejecuciones extrajudiciales, de detenciones arbitrarias y torturas, de secuestros y desapariciones forzadas, sino que a la par de todo eso sufrieron diferentes formas de violencia sexual, que lejos de ocurrir como hechos aislados se convirtieron en una práctica perpetrada de manera generalizada por los diferentes actores armados — policías, militares, ronderos, subversivos- Por tal razón, fue considerada como el delito con mayor incidencia, y definida por CVR como:

... la realización de un acto de naturaleza sexual contra una o más personas o cuando se hace que esa(s) persona(s) realice(n) un acto de naturaleza sexual por la fuerza o mediante la amenaza de la fuerza o mediante coacción, como la causada por el temor a la violencia, la intimidación, la detención, la opresión psicológica o el abuso de poder contra esa(s) persona(s) u otra persona, o aprovechando un entorno de coacción o la incapacidad de esa(s) persona(s) de dar su libre consentimiento (CVR, 2003, Tomo VI: 193).

Como parte de ésta se incluyeron la prostitución forzada, uniones forzadas, esclavitud o explotación sexual, abortos forzados, embarazos forzados y violación sexual. El que la violencia sexual haya sido incluida entre los principales crímenes cometidos también responde a un intento por dar coherencia a las normas internacionales suscritas por Perú. ${ }^{10}$

${ }^{10}$ Convención sobre la eliminación de todas las formas de discriminación contra la mujer (1979), suscrita en 1982; Convención contra la tortura y otros tratos o penas crueles, inhumanos o degradantes (ONU, 1984), suscrita en 1988; el Estatuto de Roma que crea la Corte Penal Internacional (ONU, 1998), ratificado en 2001; Convención interamericana para prevenir, sancionar y erradicar la violencia contra la mujer (Convención de Belém do Pará), suscrita en 1996; Convención interamericana 
La CVR considera la violencia sexual contra la mujer, de acuerdo con el Derecho Internacional de los Derechos Humanos, como una violación per se de los derechos humanos y, perpetrada en relación con el conflicto armado interno habido en el Perú, como una transgresión grave del Derecho Internacional Humanitario. Esta violencia, además... constituye un crimen de lesa humanidad, al alcanzar caracteres de generalizado, en algunos casos, y de sistemático, en otros (ídem: 194).

Por lo tanto, este tipo de violencia dejó de ser pensada como un efecto colateral, para ser considerada como el principal delito cometido en contra de las mujeres. Tal y como fue señalado en el Informe, la violencia sexual, y de manera particular la violación, "configuran un delito que es tipificable bajo la forma de tortura, tratos o penas crueles, inhumanos o degradantes" (ídem: 192).

A lo largo de los nueve tomos del Informe Final de CVR se articuló una narrativa que incluyó de manera transversal la perspectiva de género. De manera específica, en el Tomo VI sobre los "Patrones en la perpetración de crímenes y violaciones de los derechos humanos", se abordó lo referente a la "violencia sexual contra la mujer". En ese apartado, se presentan los diferentes contextos en que se dieron casos de violencia sexual, separando responsabilidades entre los grupos subversivos y las fuerzas del Estado, y discerniendo diferentes objetivos de esa práctica. Asimismo, en el capítulo 2 del Tomo VIII, indagaron los factores que hicieron posible la violencia generalizada, analizando el impacto diferenciado por género; en ese espacio se reflexionó sobre la violencia y la desigualdad de género como un problema estructural que existía y que pervivió al conflicto. Pero es principalmente en el capítulo referente a la violencia sexual que encontramos testimonios que dan cuenta de la narración articulada sobre este tema.

De acuerdo con las conclusiones presentadas, la violación sexual — considerada como una de las formas más radicales de la violencia sexual- adquirió dimensiones importantes a lo largo del conflicto al haber sido utilizada en diferentes contextos: desde las incursiones

para prevenir y sancionar la tortura (OEA, 1985), aprobada en 1990. 
policiacas y militares a comunidades, a las detenciones arbitrarias en cuarteles y centros de reclusión, tanto en el campo como en las ciudades; perpetrada por todos los actores armados contra cualquier mujer, estuviera o no involucrada con alguno de éstos; y teniendo, por supuesto, numerosas consecuencias para ellas.

Asimismo se señaló el perfil sociodemográfico de las víctimas. Sobre esto se concluyó que la mayoría fueron mujeres (98\%), de origen rural (83\%) y analfabetas, de las cuales $75 \%$ era quechuablante, algunas campesinas (36\%) y otras amas de casa (30\%). La mayor parte de ellas tenía entre 10 y 30 ańos (CVR, 2003, Tomo VI: 199-204). Como se observa, se trató de mujeres, en su mayoría indígenas, que forman parte de los sectores más excluidos y marginados de la sociedad peruana; es decir, no fue una práctica cometida de manera focalizada contra mujeres involucradas con las guerrillas. En cuanto a los responsables, dedujeron que cerca de $83 \%$ de las violaciones es atribuible a los agentes del Estado y $11 \%$ a los grupos subversivos -PCP-SL y MRTA (ídem: 266).

\section{Construyendo la memoria histórica}

Como producto del trabajo realizado por la Comisión, se articuló una narrativa sobre la violencia de género durante el conflicto armado, la cual se incluyó - como se explicó antes- de manera transversal a lo largo del Informe Final, además del apartado específico sobre la violencia sexual en el que se condensan aportes importantes. Revisemos algunos de éstos:

De los más significativos fue establecer que la violencia sexual constituyó una violación de los derechos humanos de las mujeres y en algunos casos un crimen de lesa humanidad y no un "daño colateral". Indudablemente esto constituye un hito importante en la región latinoamericana, ya que por primera vez se hizo un reconocimiento público oficial de esta índole.

Otro aspecto a resaltar es que el grueso de los testimonios utilizados por CVR provino de mujeres, lo que aportó una perspectiva diferente de lo acontecido, no porque se dejara de atestiguar sobre los crímenes perpetrados contra las comunidades o contra los hombres, sino porque 
se convirtieron en testigo predilecto; ${ }^{11}$ lo que implica que no sólo se trató de una diferencia cuantitativa sino cualitativa, en el sentido de que las mujeres no rememoran lo mismo ni lo narran de la misma manera que los hombres (CVR, 2003, Tomo VIII: 51). Ya Jelin (2002) había propuesto el término de memorias de género para subrayar las diferencias en cómo recuerdan hombres y mujeres, mientras que Theidon sugiere el de especialización de la memoria para indicar que hay una división del trabajo emocional en las comunidades andinas donde el sufrimiento y el luto son "trabajo de las mujeres" (2004: 264).

En función de lo anterior, habría que recuperar los efectos diferenciados de la violencia y recordar que los hombres fueron las principales víctimas mortales y el grueso de los desaparecidos, mientras que las mujeres integraron parte de las poblaciones que en un primer momento se quedaron en los lugares de origen y que después se desplazaron masivamente haciéndose cargo de la subsistencia de las familias así como de las pérdidas, incluidas las humanas y materiales.

Como sobrevivientes, ellas contaron en primera instancia lo que sucedió con sus padres, maridos, hijos y comunidades. Sólo después enunciaron los abusos o crímenes cometidos directamente en contra de ellas, aunque éstos figuraron muchas veces en segundo plano. Como se mencionó anteriormente, aunque la narrativa de CVR se apoyó en un alto porcentaje de testimonios femeninos, éstos no constituyen necesariamente relatos en primera persona, mucho menos cuando se trata de narrar hechos de violaciones sexuales. La mayoría de las mujeres que brindaron su testimonio ponderaron lo que ocurrió a los demás o a las comunidades en conjunto, develando sus propias tragedias como algo más de lo que pasó, o restándole importancia frente a otras agresiones.

Varios autores advierten sobre esto. Por ejemplo, Theidon señala que "no obstante y de manera abrumadora, ellas no hablaban en primera

11 "Jelin aborda este fenómeno desde el papel del testimonio — de testigo- de las mujeres y lo explica a través de la ética del cuidado: Muchas mujeres narran sus recuerdos en la clave más tradicional del rol de mujer, la de 'vivir para los otros'. Esto está ligado a la definición de una identidad centrada en atender y cuidar a otros cercanos, generalmente en el marco de relaciones familiares..." (citado en Vargas, 2011: 119), implica también que, a menudo, las mujeres narren en tercera persona. 
persona en el caso de las violaciones. Por tanto la queja de que 'las mujeres no hablaban' cambió a 'las mujeres no hablan sobre sí mismas', aunque sí sobre el sufrimiento de sus familiares y el daño causado a sus seres queridos" (2006: 75). En contraste, Mantilla sugiere que el trabajo con la perspectiva de género implicó que no sólo contaron las historias de las violaciones, sino que se trató de "resaltar el rol desempeñado por las mujeres en la recuperación de la memoria histórica, sobre todo porque muchos de los varones habían desaparecido o habían muerto y eran las mujeres quienes brindaban la información con la que la CVR trabajaba” (2006: 360-361). Por su parte, Vargas enfatiza en la necesidad de articular los relatos con las medidas de justicia y reparación, pues advierte: "Los relatos y testimonios son sólo la primera dificultad cuando se intenta generizar el trabajo de las CVR; la reconstrucción de la verdad y su generización debe ir acompañada de medidas de justicia y reparación...” (2011: 119). Si bien estos autores han analizado desde diversas ópticas la manera como las mujeres se vieron involucradas en el trabajo de la reconstrucción del pasado por parte de CVR, subrayan varios elementos que forman parte de la narrativa sostenida en la Comisión.

Es cierto, como indica Theidon (2006), que las mujeres no hablaron sobre sí mismas, y que cuando contaron hechos de violencia sexual —violación- casi siempre lo hicieron en tercera persona, quitándole importancia frente a otros aspectos que tienen que ver más bien con la ética del cuidado — según señala Jelin (2002) —, es decir, con su rol como madres y esposas y en cómo el conflicto imposibilitó cumplirlo. Sin embargo, consideramos que fue justo eso lo que permitió ampliar el marco narrativo de cómo las mujeres y sus comunidades vivieron el conflicto, al considerar otros aspectos menos visibles en las grandes historias sobre las proezas militares, logrando así rescatar la dimensión de lo cotidiano durante el conflicto.

Incluir la voz de las mujeres permitió a CVR construir un relato más sensible con las víctimas. Por ello, como sostiene Vargas (2011), los relatos y testimonios son la primera dificultad, obtenerlos requiere un gran esfuerzo, y lograrlo no implicó que siempre se consiguiera la anécdota que se buscaba, en este caso, la violación sexual contada en primera persona; por tanto, el siguiente reto fue valorarlos e integrarlos 
al conjunto del relato histórico. De hecho, la propia CVR señala de manera explícita en su Informe que:

Las mujeres tienen un modo particular de situarse en la historia y sus relatos del conflicto reproducen los roles que desempeñan en la sociedad. Ellas son madres, esposas e hijas de "otros" y reclaman justicia "para los otros". Practican así una "moral del cuidado" (Gilligan, 1990) que, si bien beneficia a quienes las rodean, en muchas ocasiones actúa en perjuicio de las propias mujeres. En la memoria de la violencia en el Perú, esto se ha expresado en la invisibilidad de la historia de las violaciones de los derechos humanos y de los padecimientos generales de las mujeres de los andes rurales, de las ciudades y de la selva amazónica, invisibilidad que en este capítulo se desea remediar (CVR, 2003, Tomo VIII: 47-48).

Como se aprecia, para CVR fue importante subrayar la manera como las mujeres articularon sus relatos sobre el conflicto, pues esto da cuenta de lo que ellas recuerdan y/o cómo lo recuerdan. Así, la narrativa construida por CVR, al incluir por primera vez un análisis diferenciado sobre los impactos del conflicto en hombres y mujeres, reconoció la importancia de lo que ellas tenían que decir al respecto. Esto las colocó dentro del relato nacional sobre la reconstrucción del conflicto, y con ello CVR evitó que la desigualdad de género se expresara - como lo señala la propia Comisión- como una memoria de la violencia que ignorara o relegara la historia de las mujeres en ese proceso (ídem: 47).

De ese modo y pese a las dificultades, CVR logró reunir una importante cantidad de testimonios que aunados a trabajos de índole académico - principalmente realizados por un grupo de profesionales de la historia, la sociología y la antropología - permitió construir una versión sobre el pasado reciente en Perú que incluye la voz de las mujeres, que goza de aceptación social y que se instituyó como parte de la memoria histórica sobre el conflicto armado. 


\section{Silencios y memorias de la violencia sexual}

Además de los aportes antes reseñados, queremos retomar por último cierto aspectos que constituyen algunas críticas al trabajo de inclusión de la perspectiva de género en CVR que traen a colación una de las inquietudes reflexivas de este artículo: quiénes recuerdan y cómo lo hacen, y la manera en que los testimonios se recopilaron e incluyeron en el gran relato nacional construido por CVR. A lo anterior podemos agregar que en el caso de las violaciones sexuales es más necesaria o útil la memoria que el silencio, de esta manera se plantea cómo articular una narrativa sobre una experiencia que resulta tan difícil de significar y que se identifica más con la memoria traumática que provoca grietas en la mencionada capacidad narrativa. Más aún, cómo integrar esas narrativas a las memorias colectivas que se mantienen sordas y prejuiciadas frente a esta experiencia. Cómo romper el silencio.

Un primer aspecto que no se puede dejar de mencionar es el trabajo de recopilación de testimonios, en donde la mediación de la entrevista fue fundamental para obtener la información que se buscaba. Como mencionamos anteriormente, se elaboraron guías $y$, según refiere Mantilla: "Básicamente, las sedes trabajaban enfatizando las preguntas relativas a los casos de violencia sexual, durante la toma de entrevistas" (2006: 354). En relación con esto, se puede observar cómo la mediación no escapó al requisito de enfatizar o poner especial atención en la obtención de registros sobre violencia sexual y sobre todo de las violaciones:

... la persona a cargo de la toma de testimonios debía tener esta preocupación especial por incluir las voces de las mujeres y, para el caso específico de la violencia sexual, debía asumir el silencio inicial que caracteriza estas situaciones, creando el clima de confianza suficiente para que la testimoniante superara el temor y vergüenza naturales. Era necesario tener la suficiente sensibilidad para no forzar a la víctima a hablar si es que no deseaba hacerlo, pero tampoco dejar de lado información importante... Era necesario incluir entre el repertorio general de preguntas de la entrevista algunas que ayudaran a determinar la existencia de hechos de 
violencia sexual, las cuales debían hacerse permanentemente a todas las personas que se acercaban a la CVR. La idea era preguntar de manera general si la persona testimoniante conocía de casos de violencia sexual en su comunidad. Si la respuesta era afirmativa, se debía profundizar la entrevista tratando de determinar algún caso específico, con la mayor información posible en relación a la identidad de la víctima, del agresor, el lugar, la fecha, etc. Este tipo de preguntas resultaba fundamental ya que en muchas ocasiones los varones podían dar esta información con mayor facilidad que las mujeres (ídem: 356).

Por ello se debe ponderar el hecho de que la propia Comisión inclinó la balanza de las experiencias de las mujeres durante el conflicto hacia las narraciones o testimonios que refirieron agresiones de carácter sexual, esto pudo representar una fuerte presión para que las mujeres hablaran sobre algo a lo que socialmente se le impone el silencio. Obviamente se requería de una estrategia para acercarse a las mujeres e indagar sobre casos de violaciones sexuales.

Sin embargo, la aproximación entre el emisor y el receptor de esas entrevistas se puede imaginar llena de tensiones entre la incapacidad de narrar o el deseo de no hacerlo y la urgencia por develar y comprobar las atrocidades cometidas en contra de ellas. Por supuesto, era difícil cuando constituyen una constante en las experiencias de las mujeres en contextos armados, pues es innegable que la violencia sexual es uno de los principales riesgos para ellas.

Una de las principales críticas ha sido que al enfatizar ese aspecto se puede revictimizar a las mujeres e invisibilizar, opacar o restar importancia a otros hechos que también narran en sus testimonios sobre cómo vivieron el conflicto, a los que ellas mismas dan mayor peso como otras agresiones o consecuencias. Una segunda digresión digna de comentar - vinculada a la anterior - tiene que ver con que pese a que se buscara el dato sobre la violación sexual y se sensibilizara al personal encargado de ello, en la mayoría de los testimonios las mujeres hicieron referencia a diferentes formas de violencia sexual a que fueron 
sometidas, ${ }^{12}$ pero muy pocas hablaron de violaciones sexuales; no obstante, se articuló una narrativa, en extenso, sobre la violencia sexual, la violación y sus efectos.

En este sentido, la crítica sugiere que aunque las mujeres prefirieron callar respecto a las violaciones sexuales, su silencio no fue respetado. ${ }^{13}$ Sobre esto, Theidon afirma que "a pesar de tantas estrategias implementadas para asegurar 'que hablen las mujeres' [preguntémonos si las entrevistas de CVR fueron una de estas estrategias], de forma contundente las mujeres quechuahablantes han preferido el silencio ... Vale recordar que en ciertos caso la violación fue utilizada para forzar a las mujeres a hablar" (2009: 12); y anota que en las mujeres reposa una carga narrativa sobre estos hechos: "son las mujeres quienes están incitadas a hablar sobre la violencia sexual; el silencio de los violadores no se perturba ... Empero las mujeres rutinariamente están obligadas a narrar sus experiencias en un idioma de la vulnerabilidad sexual y la degradación” (ídem: 11).

Su sentencia es mordaz pero pone de manera acertada el dedo en la llaga. Antes dijimos que si existe un tema capaz de imponer silencio es la violación sexual; esto fue percibido por quien escribe, en más de un trabajo me he cuestionado sobre cómo interpretar esos silencios, cómo determinar cuándo pueden constituir agencia, y he defendido el derecho de las mujeres a guardar silencio.

Como hemos venido mencionando, obtener este tipo de relatos compromete demasiado a las mujeres, por ello no es de extrañar que lo contaran en tercera persona. Algo particularmente interesante es

\footnotetext{
${ }^{12}$ Algunas de las prácticas de violencia sexual recurrentes durante el conflicto fueron: amenazas de violación, mantenerlas desnudas durante las detenciones en bases militares, toqueteos de los cuerpos de las mujeres durante las detenciones, así como en las comunidades indígenas a las que llegaban y se instalaban los militares; también, aun y cuando no las tocaban, las obligaron a realizar acciones denigrantes como simular posiciones sexuales y fingir masturbaciones. Asimismo, podemos mencionar golpes y otras formas de tortura en los órganos sexuales, y el caso de mujeres embarazadas que fueron golpeadas en el vientre hasta provocarles abortos.

${ }^{13}$ Kimberly Theidon ha escrito sobre esto en un artículo titulado "La teta asustada: una teoría sobre la violencia de la memoria”, en Praxis: un instituto para la justicia social, 2009, [en línea] disponible en http://www.pueg.unam.mx/images/ seminarios2015_1/ critica_cultural/the_kim.pdf [fecha de consulta: 15 de octubre de 2014].
} 
que los hombres que dieron su testimonio también contaron sobre las violaciones sexuales del mismo modo, refiriéndose a cuando los soldados llegaban y abusaban de las mujeres. Siempre narrando de manera impersonal.

Valdría la pena preguntarnos si el hecho de que estos actos hayan sido narrados por otras personas, en calidad de "testigos", podría suponer que la violación sexual de mujeres forma parte de la memoria colectiva sobre la violencia durante el conflicto armado y de cómo estos sucesos afectaron, de algún modo, al colectivo —familias, comunidades, poblados-; pensemos en los familiares, vecinos o conocidos que fueron obligados a presenciar estos hechos. Quizá no encontremos una respuesta por el momento, aunque nos orilla a pensar en otras posibilidades. De nuevo, las preguntas aparecen: ¿olvidar?, ¿̇recordar?

Reestructurarse a sí mismas después de un acto de esta naturaleza y poder elaborar una memoria articulada sobre dicha experiencia no es cosa fácil. Menos cuando no se cuenta con los canales adecuados para ser escuchadas y recibir un poco de compresión, por el contrario, son juzgadas y estigmatizadas socialmente. Por esa razón, en la memoria histórica sobre la violencia sexual durante el conflicto armado, subyacen otras memorias que no encuentran un espacio apropiado para ser contadas y/o elaboradas. Esas memorias tienen que ver con los silencios; silencios que en algunos casos fueron voluntarios y en otros impuestos.

No es raro que muchas mujeres hayan optado por mantener en secreto sus historias sobre violaciones sexuales cuando, mucho antes del surgimiento de CVR, se sabía que ocurrían —era un secreto a voces-. Aunque se habían denunciado algunas, éstas no prosperaron. En muchas comunidades las mujeres que se quedaron solas con sus hijos se convirtieron en blanco de ataques sexuales por parte de todos los actores armados. Ellas resistieron estoicamente los horrores que les infligieron. No obstante, una vez que terminó el conflicto y se restableció cierta normalidad en sus comunidades, no siempre pudieron contar todo lo que vivieron.

Muchas veces, y quizá en la gran mayoría de los casos — como se lee a lo largo del Informe Final de CVR-, pudieron articular una memoria más comunitaria y en tercera persona sobre cómo sus comunidades 
fueron atacadas, cómo perdieron a sus familiares —esposos e hijos, principalmente-, cómo se desplazaron a otras zonas, etcétera; pero poco dijeron en primera persona sobre sus experiencias más "íntimas" sobre la violencia, muchas prefirieron "olvidar" u optaron por el silencio.

El silencio impuesto o autoimpuesto respecto a una violación sexual manifiesta la carga valorativa construida sobre la sexualidad de las mujeres, así como el lugar e importancia de ésta dentro de las relaciones de género. Lo anterior, por ejemplo, se refleja en la imposibilidad que muchos hombres tienen para aceptar la convivencia con una mujer que fue violada, "que ha sido de otro hombre", sin considerar que fue por la fuerza; como si se tratase de una cuestión de propiedades que no están dispuestos a compartir. Por ello, como se lee en algunos testimonios, no se denunciaba "por temor ... y también por la dignidad".

Muchas prefirieron callar porque sólo deseaban olvidar. En ese sentido, el silencio pudo ser un mecanismo para borrar de su memoria un evento traumático, pero también pudo ser utilizado para prevenir el estigma frente a la familia e incluso ante la comunidad; sabían del costo social —estigma, críticas, abandono de sus maridos- ${ }^{14}$ que su palabra o denuncia podría tener. Y, como la misma CVR subraya:

No se trata de un evento pasajero; sus consecuencias son de largo plazo. Malograr, estropear, dañar, estas palabras, utilizadas en los testimonios, remiten a experiencias más duraderas, severas y terminales. La violencia sexual deja huellas visibles en el cuerpo, pero también marcas invisibles en la vida mental y afectiva, así como en la vida social, mediante la privación del reconocimiento y el respeto comunal ... La información recogida por la CVR muestra que, en muchos casos, las mujeres no anunciaban las violaciones por temor o vergüenza, pero también porque tenían la convicción de que cualquier reclamo sería inútil por las circunstancias de

\footnotetext{
${ }^{14}$ Evidentemente, tanto la denuncia como el silencio tienen costos sociales y personales significativos. Y aunque en torno a esto es que se constriñe, en parte, este debate sobre la violencia sexual, no debemos perder de vista las implicaciones que cada una tiene, aun y cuando, consideramos que la decisión —no la imposición— de hablar o callar debe ser respetada.
} 
arbitrariedad e impunidad en las que se cometieron los abusos, para no mencionar la corrupción e ineficacia imperantes en el sistema de administración de justicia. Otros testimonios señalan más bien que las mujeres no denunciaban por miedo a ser culpabilizadas y para evitar el estigma público que cae sobre la mujer violada sexualmente (2003, Tomo VIII: 69).

Se aprecia, tanto en lo referido como en el relato de CVR, que esto constituyó una dificultad para dar sentido a la experiencia de las violaciones sexuales e integrarlas a la narrativa histórica del conflicto. Más adelante, y siguiendo la relación temporal de la memoria, CVR establece que la violencia sexual implica un desarraigo y ruptura del lazo social que "atenta contra la posibilidad de rehacer su vida y mirar hacia el futuro. El pasado es un presente que le niega un futuro posible” (ídem: 75).

\section{Reflexiones finales}

Hemos visto que CVR no se muestra ajena a los avatares de la memoria $\mathrm{y}$ reconoce las posibilidades que encierra su narrativa hacia el futuro $y$ todas sus acotaciones. Sin embargo, aunque tomemos en cuenta - de acuerdo con el planteamiento de Carlos Vargas - el potencial que tiene la Comisión de la verdad para generar narrativas alternas, subsisten algunas preguntas.

Si la memoria social es importante como fenómeno colectivo porque la rememoración del pasado reciente "trasciende a las víctimas individuales, a los recuerdos subjetivos y personalísimos, y da cuenta de los impactos sociales de un pasado particular" (Vargas, 2011: 113), ¿cómo insertar en esa memoria colectiva las historias de la violaciones sexuales no contadas ni escuchadas, por no haber encontrado un espacio capaz de retribuir "algo" de lo perdido o generar algo de resonancia?

De acuerdo con Jelin, "escuchar a otros con capacidad de escuchar es central en el proceso de quebrar silencios” (2002: 32). Quebrarlos, abre la posibilidad de la significación de la experiencia; y en ese sentido, quizá uno de los mayores problemas de cómo entender la violencia sexual tiene que ver con que en muchas de sus formas es parte de la 
cotidianidad para muchas mujeres, de tal modo que antecede, subsiste, se agudiza y persiste al conflicto, y de cierta manera lo trasciende, pues forma parte de lo que ya era silenciado por la sociedad, y no sólo por ellas. A diferencia de otros crímenes y violaciones de los derechos humanos como la desaparición, la tortura o las masacres, que escapan a la cotidianidad que se vivía antes de los conflictos y por ello son vividos y entendidos como algo ajeno a la normalidad de la vida, a lo aceptable.

Por otra parte, interesa señalar que esta reflexión nos permite apuntalar ahora otro tipo de cuestionamientos al propio trabajo de CVR, en tanto que la perspectiva de género se focalizó en la construcción de la narrativa relacionada con la violencia sexual, que derivó en una construcción problemática de las mujeres como "víctimas".

Importa subrayar que pese a las pretensiones de CVR de construir un relato más sensible con "las víctimas" y lograr un análisis diferenciado sobre los impactos del conflicto en hombres y mujeres, reconociendo la importancia de lo que ellas tenían que decir, derivó en una historia que de manera paradójica, al integrar los testimonios de las mujeres, amplió el marco narrativo de cómo ellas y sus comunidades vivieron el conflicto, al mismo tiempo que enfatizó tanto en la violencia sexual que redujo la perspectiva de género a historias de mujeres sobre esta forma de violencia, aun y cuando ellas insistían en ampliar el marco narrativo de sus experiencias.

La pregunta final versa sobre la posibilidad de que algún día sea posible articular una narrativa sobre la violencia sexual que la trascienda como violencia cotidiana - que la mueva del lugar que ocupa en el imaginario social como violencia estructural, forma de discriminación e inequidad de género- $y$ le ayude a ocupar un lugar significativo junto a las consideradas como "violaciones extremas". Finalmente, un problema que subyace a todo lo anterior es que históricamente las mujeres han sido excluidas de la forma de representar la propia historia y de la toma de decisiones sobre cuestiones que también les afecta; por lo regular no es lo que ellas pueden decir porque no son pensadas como sujetos de derecho, ni se reconoce su agencia. 


\section{Bibliografía citada}

Braunstein, Néstor A., 2012, La memoria del uno y la memoria del Otro: inconsciente e historia, Siglo XXI Editores, México.

Comisión de la Verdad y Reconciliación de Perú, sin fecha, "Balance. Informe sobre las actividades realizadas por la Comisión de la Verdad y Reconciliación y convocatoria al país", Perú, disponible en http://www.cverdad.org.pe/ingles/lacomision/balance/ index.php [consultado en línea el 30 de octubre de 2014].

Comisión de la Verdad y Reconciliación de Perú, 2002a, "Boletín de la Comisión de la Verdad y Reconciliación”, núm. 1, abril 2002, [en línea] disponible en http://www.cverdad.org.pe/ informacion/boletines/pdfs/boletin1.pdf [fecha de consulta: 20 de diciembre de 2014].

Comisión de la Verdad y Reconciliación de Perú, 2002b, “Acuerdo de Comisionados. Incorporación de la perspectiva de género en el trabajo de la Comisión de la Verdad y Reconciliación (CVR)", mayo, Lima, Perú, disponible en http://www.cverdad.org.pe/ lacomision/nlabor/ documentos01.php [consultado en línea: 30 de octubre de 2014].

Comisión de la Verdad y Reconciliación de Perú, 2003, "Informe Final”, Perú, disponible en http://www.cverdad.org.pe/ifinal/index.php [consultado en línea: 30 de octubre de 2014].

Del Pino, Ponciano, 2004, "Violencia, memoria e imaginación. Uchuraccay y Lucanamarca en la violencia política en el Perú", en Boletín IFP Derechos Humanos, junio, año 1, núm. 7, pp. 11-13, [en línea] disponible en http://www.insumisos.com/lecturasinsumisas/Violencia_memoria \%20e\%20imaginacion.pdf [fecha de consulta: 8 de abril de 2014].

Halbwachs, Maurice, 2004, Los marcos sociales de la memoria, Anthropos, Barcelona, España.

Jelin, Elizabeth, 2002, Los trabajos de la memoria, Siglo XXI, España. Jelin, Elizabeth, 2003, "Los derechos humanos y la memoria de la violencia política y la represión: la construcción de un campo nuevo en las ciencias sociales", en Cuadernos del IDES, núm. 2, octubre, Cuadernos del Instituto de Desarrollo Económico 
y Social, Buenos Aires, [en línea] disponible en http://www. cipae.org.py/V2/uploads/2009/08/cuaderno2_jelin.pdf [fecha de consulta: 20 de mayo de 2014].

Le Goff, Jacques, 1991, El orden de la memoria: el tiempo como imaginario, Paidós, Barcelona, España.

Maceira Ochoa, Luz y Lucía Rayas Velasco, 2011, Subversiones: memoria social y género. Ataduras y reflexiones, INAH/Conaculta, México.

Mantilla, Julissa, 2006, "La Comisión de la Verdad y Reconciliación en el Perú y la perspectiva de género: principales logros y hallazgos", en Revista IIDH, enero-junio, núm. 43, pp. 323-365, San José, Costa Rica.

Ricoeur, Paul, 1999, La lectura del tiempo pasado: memoria y olvido, Universidad Autónoma de Madrid, Arrecife, España.

Ricoeur, Paul, 2010, La memoria, la historia y el olvido, Editorial Trotta, Madrid, España.

Sarlo, Beatriz, 2005, Tiempo pasado: cultura de la memoria y giro subjetivo, Siglo XXI Editores, Buenos Aires, Argentina.

Theidon, Kimberly, 2004, Entre prójimos. El conflicto armado interno y la politica de la reconciliación en Perú, IEP, Lima, Perú.

Theidon, Kimberly, 2006, "Género en transición: sentido común, mujeres y guerra”, en Cuadernos de Antropología Social, núm. 24, pp. 69-92, Universidad de Buenos Aires, Argentina.

Theidon, Kimberly, 2009, "La teta asustada: una teoría sobre la violencia de la memoria", en Praxis, Instituto para la Justicia Social, [en línea] disponible en http://www.pueg.unam.mx/images/seminarios2015_1/ critica_cultural/the_kim.pdf [fecha de consulta: 15 de octubre de 2014].

Todorov, Tzvetan, 2000, Los abusos de la memoria, Paidós, Barcelona, España.

Traverso, Enzo, 2007, El pasado, instrucciones de uso. Historia, memoria, politica, Ediciones Jurídicas y Sociales, Madrid. 
Vargas Tames, Carlos, 2011, “De la generalización a la generización de la memoria. El caso de las comisiones de la verdad y la reconciliación", en Luz Maceira Ochoa y Lucía Rayas Velasco (editoras), Subversiones: Memoria social y género. Ataduras y reflexiones, pp. 103-129, INAH/Conaculta, México. 